\title{
CONFIRMATORY FACTOR ANALYSIS OF THE VALENCIA SCALE ON ATTITUDES AND BELIEFS TOWARD HYPNOSIS: An International Study
}

\author{
ANTONIO CAPAFONS, SONIA CABANAS, \\ AND BEGOÑA ESPEJO ${ }^{1,2}$
}

University of Valencia, Spain

\author{
ETZEL CARDEÑA
}

University of Texas-Pan American, Edinburg, USA

\begin{abstract}
Cognitions held about hypnosis have an important impact on areas such as initial rapport and hypnotic-treatment compliance. The Valencia Scale on Attitudes and Beliefs toward Hypnosis may be the first instrument specifically geared to the Spanish-speaking population. Besides measuring these cognitions, the scale can also help evaluate the effect of clinical and experimental manipulations on people's attitudes and beliefs toward hypnosis. The article pres-
\end{abstract}

Manuscript submitted January 25, 2003; final revision received June 4, 2003.

${ }^{1}$ The following colleagues helped with data acquisition: Francisco Aliaga, Carmen Casas, Amparo Cotolí, Inmaculada Fuentes, Diana Pons, and Consuelo Roldán (Universitat de Valéncia, Spain); Arturo Bados (Universidad de Barcelona, Spain); Agustín Bayot (Universidad de Castilla La Mancha, Spain); Adolfo Cangas (Universidad de Almería, Spain); Juan Capafóns (Universidad de La Laguna, Spain); Juan Ramón Lamas (Universidad de La Coruña, Spain); Lorena Melich and Laura Xuclà (Universidad de Rovira i Virgili, Spain); Benjamín Membreño (Universidad José Cecilio del Valle/ Catholic University of Honduras); Emilio Mirambell (Universidad de Alicante, Spain); Jenny Moix (Universidad Autónoma de Barcelona, Spain); Miguel Navarro (Universidad Complutense of Madrid, Spain); Alberto Rybka (Private practice, Argentina); Julio Santana (Universidad Médica de Gramma, Cuba); Margarita Tallo-Ortiz (Universidad de Málaga, Spain); Mónica Tesone (Private practice, Argentina); Pedro H. Torres (Universidad Miguel de Cervantes, Chile); and Miguel Ángel Vallejo (Universidad Nacional de Eduación a Distancia, Spain).

${ }^{2}$ Address correspondence to Etzel Cardeña, Ph.D., Professor and Director of Graduate Program, Department of Psychology and Anthropology, University of Texas-Pan American, 1201 West University Drive, Edinburg, TX 78539 USA. E-mail: ecardena@panam.edu

Address request for reprints to Dr. Cardeña or to Antonio Capafons, Ph.D., Facultat de Psicología, Universitat de Valéncia, Avda. Blasco Ibáñez \#21, 46010 Valencia, Spain. E-mail: Antonio.Capafons@uv.es 
ents a confirmatory factor analysis using a sample from 5 different countries $(N=2,402)$. Test-retest analyses were also carried out. The authors found statistical confirmation for an 8-factor model solution: automatism, help, personal control, interest, magical solution, collaboration, memory, and marginal.

The interest in the study of the attitudes and beliefs toward hypnosis has had a recent resurgence (Green, 2003). Various studies have shown that samples of nonspecialists tend to hold erroneous beliefs and stereotypes about the nature of hypnosis, the impact of suggestions, the role of the hypnotist, and the role of the hypnotized person (McConkey, 1986). Nonetheless, when evaluating the literature on "misconceptions" about hypnosis, two problems should be borne in mind. The first one is that vague and polysemantic concepts such as "trance" may give a more or less distorted notion of hypnosis depending on which of the various senses of the term is being used (Cardeña, 1990). The second problem is that statements treated as misconceptions, such as the notion that hypnosis involves an "altered state of consciousness," may not necessarily be erroneous for a particular respondent. Some hypnotized individuals do report bona-fide discreet alterations of consciousness (Barber, 1999; Cardeña, 2003; Cardeña \& Spiegel, 1991), although these experiences do not seem to be indispensable to obtain various hypnotic effects.

London (1961) found a great number of stereotypical opinions among undergraduates. McConkey (1986) got similar results including the attribution of hypnosis to an altered state of consciousness in which experiencing suggestions does not require effort on the part of the person and in which some events may be recalled that could not be recalled otherwise. In the clinical arena, Bryant (1993) observed similar opinions regarding the application of hypnosis to pain. In a study elucidating the difference between beliefs and experiences, Meyer and Lynn (2002) found that although subjective experiences of entering a "trance" and a state of focused attention were correlated with hypnotic suggestibility, beliefs that "trance" and a state of focused attention are related to hypnosis did not correlate with actual suggestibility. They also reported that positive attitudes toward hypnosis and lack of fear were related to hypnotic suggestibility, response expectancies, and reported depth of hypnosis.

McIntosh and Hawney (1983) concluded that clients who know hypnosis only through TV or stage hypnosis develop negative opinions toward it and consider it a clinically worthless technique. Consistent with this conclusion, a recent study by Gow, Mackie, Clohessy, Cowling, and Maloney (2002) with an Australian general-population sample found that exposure to television and stage depictions of hypnosis were significant predictors of the misconceptions that the hypnotist controls the experience and that individuals cannot lie or fake during hypnosis. Experiencing stage hypnosis was related to the notion 
that hypnosis can create "abnormal behavior," whereas personal experience with a health professional made people more open to hypnosis. The authors report 11 factors extracted from various attitudes and opinions toward hypnosis: memory enhancement, openness, hypnotist controls the experience, negative stereotypes, fear, the client creates the experience, hypnotized person cannot lie or fake, it can be experienced by anyone, it involves an altered state, it involves abnormal behavior, and it involves pain reduction (Gow et al., 2002).

Thus, before using hypnosis as a therapeutic adjunct, it is important to evaluate the client's attitudes and resolve the associated fears and unrealistic or false expectations (Capafons, 2001; Spanos, Brett, Menary, \& Cross, 1987). Attitudes toward hypnosis can be important in a number of ways, including: (a) their influence on treatment outcomes, because positive attitudes are related to positive outcomes (Chaves, 1999; Schoenberger, Kirsch, Gearan, Montgomery, \& Pastyrnak, 1997); (b) their association with hypnotic suggestibility, because attitudes may partly mediate increases in suggestibility when paired with other variables such as actively interpreting suggestions (Meyer \& Lynn, 2002; Spanos et al., 1987); and (c) their importance in the development of rapport (Capafons, Alarcón, Cabañas, \& Espejo, 2003). Negative and unrealistic beliefs may interfere with cooperation with the hypnotist and treatment compliance.

The lack of a valid attitude-assessment instrument in Spanish led the first author and his collaborators to develop the Scale of Attitudes and Beliefs Toward Hypnosis-Client (Escala de Actitudes y Creencias hacia la Hipnosis-Cliente, or EACH-C; Capafons et al., 2003). This scale has 28 items, some of them based on the Hypnosis Survey Beliefs by Keller (1996) and other instruments (Eimer \& Freeman, 1998; McConkey, 1986; McConkey \& Jupp, 1985/1986; Nickisson, 1997; Spanos et al., 1987). The remaining items are based on the seven misconceptions about hypnosis proposed by Capafons (1998). The reply format is based on Keller's.

An exploratory analysis (Capafons et al., 2003) turned out six factors: automatism, help, personal control, interest, magical solution, and collaboration. An item was eliminated because of low loading in a factor analysis, but two items that did not have a high load on the factors were retained because they fulfilled theoretical criteria (see appendix, Items 4 and 16). The internal consistency of the scale was satisfactory, although the test-retest correlations of the factors magical solution and collaboration were only moderate $\left(r_{x y}=.54, p<.01\right.$; $r_{x y}=.39, p<.01$, respectively). The amount of variance accounted for in this exploratory analysis was: automaton $=17 \%$, help $=12 \%$, control $=8 \%$, interest $=6 \%$, magical $=5 \%$, collaboration $=4 \%$, and total variance explained $=53 \%$. The scale has shown to be sensitive to changes in attitudes and beliefs toward hypnosis brought about by interventions designed to modify them (Capafons et al., 2004). 
We then developed a new, 34-item version of the scale to be filled out by clients, the Valencia Scale of Attitudes and Beliefs Toward HypnosisClient (La Escala de Valencia de Actitudes y Creencias hacia la HipnosisCliente or EVACH-C, see appendix). We added three new items to form a new factor related to memory recollection associated with hypnosis; three other items to create a new factor of gullibility toward hypnosis, and a final item was added to the factor of magical solution. Thus, we expected that the scale would measure eight attitudinal factors: automatism, help, personal control, interest, magical solution, collaboration, memory, and marginal. Automatism refers to losing voluntary control while hypnotized; help has to do with hypnosis being helpful; personal control implies that hypnotized people control their actions and that hypnotic responses are voluntary; interest defines the interest or liking that the respondent has about being hypnotized. The fifth factor, magical solution, revolves around hypnosis being a wonderful technique to solve problems without the person having to show effort or make anything else to effect change; collaboration refers to a necessary collaboration between the hypnotist and the subject to achieve an adequate hypnotic response; memory has to do with whether hypnosis has an especial hypermnesia effect; and marginal refers to the perception that hypnosis is outside of the scientific domain, involves special processes, or that hypnotizable people are marginal. The aim of this study was to evaluate the eight-factor structure proposed from a confirmatory perspective.

We expected this structure based on the seven general stereotypes proposed by Capafons (1998), verified factorially by Capafons and collaborators (2003), in addition to a memory factor. Previously Spanos and collaborators (1987) proposed a different factor structure: positive beliefs toward hypnosis, mental stability, and fearlessness. Although the exploratory factor analysis was similar to that of Capafons et al. (2003), the latter used more items (28 vs. 14 in Spanos et al.) and had a broader coverage and a larger sample. The items by Spanos et al. evaluated beliefs about control, psychological stability, and fearlessness but did not include beliefs about memory, collaboration, hypnosis as an adjunct, etc. The scale we used has a broader coverage and an updated statistical technique.

\section{METHOD}

\section{Sample}

In the first testing, 2,402 undergraduate students from five different Spanish-speaking countries participated; $72.5 \%$ were females, the average age was $22.3(S D=5.2)$ (see Table 1$)$, and $86.2 \%$ had not been hypnotized previously. More than half $(52.3 \%)$ had not received previous information on hypnosis, and $36.9 \%$ had previous information. Of those who had previous information, $10.6 \%$ had received scientific 
Table 1

Demographics of the Sample for the Initial Testing

\begin{tabular}{lccccc}
\hline Country & Total $N$ & Women & Men & Average Age & SD \\
\hline Spain & $1817(75.6 \%)$ & $1366(56.8 \%)$ & $390(16.2 \%)$ & 22.12 & 4.64 \\
Cuba & $370(15.4 \%)$ & $274(11.4 \%)$ & $83(3.5 \%)$ & 22.56 & 7.06 \\
Argentina & $65(2.7 \%)$ & $30(1.2 \%)$ & $35(1.5 \%)$ & 22.70 & 5.15 \\
Chile & $70(2.9 \%)$ & $36(1.5 \%)$ & $34(1.4 \%)$ & 23.69 & 7.04 \\
Honduras & $82(3.4 \%)$ & $38(1.6 \%)$ & $44(1.8 \%)$ & 23.59 & 5.01 \\
Total $N$ & 2404 & $1744(72.5 \%)$ & $586(24.4 \%)$ & 22.30 & 5.20 \\
\hline
\end{tabular}

information (courses and/or scientific readings), and $12.2 \%$ had only heard about hypnosis through the media (other readings, TV, other means); the remaining did not specify the source of the information. Participation was voluntary and did not include any type of compensation. A retest included 64 participants (71\% females), none of which had been previously hypnotized nor had received information about hypnosis between the test and the retest.

\section{Procedure}

Participants were given the questionnaire and were told that their data would be anonymous and confidential, and that they should respond to the questions according to what they thought or believed about hypnosis. A subsample was retested 1 month afterward, and participants were asked to respond what they thought and believed at that moment, and not to try to remember how they had answered previously.

\section{Analyses}

In classical test theory, an observed score $X_{i}$ is decomposed into a true score and an error score. It is assumed that true and error scores are the same for each component and that error scores for different components must be uncorrelated. As was shown by Jöreskog (1971), this classical approach may be expressed in terms of a factor analytic model with one common factor. If $X_{1}, \ldots, X_{n}$ are observed scores on $n$ components designed to measure the same construct $(\xi)$, then:

$$
X_{i}=\lambda_{i} \xi+\epsilon_{i}
$$

The diagonal in the covariance matrix of the observed scores contains the variance of each observed score, and this variance is divided into a true score variance part $\left(\lambda_{\mathrm{i}}^{2}\right)$ and an error variance part $\left(\theta_{\mathrm{ii}}\right)$. The rest of the cells in the matrix contain the covariances between the scores. Following Jöreskog (1971), the reliability of a component score can be estimated according to the formula:

$$
\rho_{\mathrm{ii}}=\frac{\lambda_{\mathrm{i}}^{2}}{\lambda_{\mathrm{i}}^{2}+\theta_{\mathrm{ii}}}
$$


When the component scores are summed to give a composite score, the reliability of this composite is obtained thus:

$$
\rho_{\mathrm{xx}}=\frac{\sum-\theta^{2}}{\sum}
$$

where $\Sigma$ is the fitted variance-covariance matrix among the variables, and $\theta^{2}$ is a diagonal matrix with variances of the errors of measurement on the diagonal (Werts, Rock, Linn, \& Jöreskog, 1978). Both matrices are estimated by the LISREL program (Jöreskog \& Sörbom, 1999). If a specific factorial structure is hypothesized, this procedure makes it possible to estimate the reliability of each factor independently, but two requirements are needed to obtain a meaningful estimate: the model must be consistent with the data and the solutions for the model parameters must be unique (Werts et al., 1978).

The most commonly used measure of reliability, Cronbach's alpha, is an unbiased estimate of reliability of a composite only if the true score variances of its component scores are equal. It is assumed, then, that the loadings on the common factor are equal (Novick \& Lewis, 1967):

$$
\lambda_{\mathrm{i}}=\lambda_{\mathrm{j}}=\cdots=\lambda_{\mathrm{n}}
$$

In this case, we have a tau-equivalent measurement model, but we may assume the error variances of the component scores to be equal. In this case, we have a parallel measurement model:

$$
\theta_{\mathrm{i}}=\theta_{\mathrm{j}}=\cdots=\theta_{\mathrm{n}}
$$

When the component scores are measuring one common factor but both their factor loadings and their error variances cannot be considered equal, the measurement model is called congeneric. In this case, Cronbach's alpha underestimates the reliability of the composite score, and alpha is only a lower bound of reliability (Lord \& Novick, 1968; Novick \& Lewis, 1967). For this reason, it is important to test these models before obtaining estimates of the reliability of a composite score. LISREL allows imposing restrictions on this set of parameters and tests the goodness of fit of three measurement models.

Therefore, the first step was to test the factor structure of the scale by assuming the presence of the eight correlated factors described earlier. After excluding Item 16 of the first version of the scale, 34 items remained, of which Items 4 and 16 of the present version were taken as criterion items. The factors are: control (Items 14, 15, 20, 23, and 24); help (Items 1, 10, 12, and 22); automaton (Items 7, 11, 17, 18, 19, and 21); magical (Items 3, 5, 6, 9, and 28); collaboration (Items 2, 8, and 13); interest (Items 25, 26, and 27); memory (Items 29, 30, and 31); and marginal (Items 32, 33, and 34). To obtain the best estimates of reliability for the items and factors, we evaluated the best model to describe the data. 
The dimensionality of the scale was tested by means of a confirmatory factor analysis (CFA) of the polychoric correlation matrix and the asymptotic covariance matrix among the items. We used the maximum likelihood estimation method, as implemented in LISREL 8.30 (Jöreskog \& Sörbom, 1999). If the asymptotic covariance matrix is provided, standard errors are estimated under nonnormality and the Satorra-Bentler scaled chi-square statistic is obtained. This chisquare is used in LISREL to obtain many fit statistics that depend on it, and is automatically used in case of nonnormality (Jöreskog, Sörbom, du Toit, \& du Toit, 1999).

Some goodness-of-fit indices provided by LISREL were used then, including the root mean square error of approximation (RMSEA), a measure of the discrepancy per degree of freedom for the model (Steiger, 1990; Steiger \& Lind, 1980). A value of about .05 or less indicates a close fit of the model in relation to the degrees of freedom, and a value of about 0.08 or less indicates a reasonable error of approximation (Browne \& Cudeck, 1993). Other indices used were the adjusted goodness-of-fit index (AGFI; Jöreskog \& Sörbom, 1984, 1989), which takes into account the degrees of freedom and the parsimony goodness-of-fit index (PGFI; Mulaik et al., 1989). Both indices lie between 0 and 1 , and a value close to 1 indicates a close fit. It is possible to have acceptable models with goodness-of-fit indices of about .90 and parsimonious-fit indices of about .50, indicating that much of the good fit remains untested or unexplained. The PGFI is especially useful when comparing models because it considers not only the degrees of freedom but the parsimony of the model. It can be seen as the difference in quality of two models that fit the same data equally well but where one of the models is more parsimonious than the other (Mulaik et al., 1989). The $p$-value significance of the $\chi^{2}$ is not used as a goodness-of-fit parameter in this study. It is very sensitive to sample size so that with large samples almost every model would be rejected (Ullman, 1996).

In the first CFA, the eight-factor structure of the scale was examined and no restrictions were made on the parameters. After selecting the best congeneric models, the tau-equivalent and parallel models were tested for the global scale. To test the parallel model, equality constraints on the $\lambda_{i}$ and $\theta_{i}$ parameters were imposed for all the composites in each factor. All the items in each factor were constrained to have equal $\lambda_{\mathrm{i}}$ and equal $\theta_{\mathrm{i}}$ parameters. To test the tau-equivalent model, only equality constraints on the $\lambda_{i}$ parameters were imposed along the same lines. The tau-equivalent model is nested within the congeneric model and the parallel model is nested within the tau-equivalent model. A set of restrictions could be inappropriate if the goodness of fit of a more restricted model is significantly worse than the goodness of fit of a less restricted model. One approach to model comparisons is based on 
differences in chi-square values of the different models. A statistically significant chi-square difference would suggest that the less restrictive model is preferable.

After the analysis of the test data, the stability of the measure was studied. Although the test-retest correlation is a common reliability estimate, these correlations can lead to biased reliability estimates if there is instability in the true scores in the interval between tests or if the measurement errors are correlated (Blok \& Saris, 1983; Werts, Breland, Grandy, \& Rock, 1980). This could lead to underestimating the real correlation between test and retest measures. Because the retest sample was too small $(n=64)$ to assess longitudinal stability from a covariance structure analysis perspective, $t$ tests were calculated on the composite score of each factor, expecting to find no statistically significant differences, in the absence of a specific manipulation to change attitudes and beliefs.

\section{RESULTS}

\section{Test}

The model tested assumed the eight correlated factors described in the introduction. The goodness-of-fit indices obtained for the eightfactor model (Model 1) indicated acceptable fit of the data (see Table 2), but the modification index (MI) associated with the correlation between the errors of Items 6 and 28 was very high $\left(\mathrm{MI}_{\theta 6.28}=1046.03\right)$. This suggested a second dimension for these items. After freeing the covariance between the errors of these items, the model provided better fit to the data $\left(\chi_{\text {dif }}^{2}=67.15, d f_{\text {dif }}=1, p<.01\right)$. Then, the item with the smallest factor loading in this pair (Item 28) was removed from additional analyses.

The goodness-of-fit indices obtained for the eight-factor model without Item 28 (Model 2) are shown in Table 2. As can be seen, this model provided a better fit than Model 1. Again, another MI associated with the correlation between the errors of two items was very high, $\mathrm{MI}_{17,19}=1262.75$. This parameter was set free, and an improvement in the goodness of fit was observed $\left(\chi_{\text {dif }}^{2}=138.64, d f_{\text {dif }}=1, p<.01\right)$.

Table 2

Goodness-of-Fit Indices of the Congeneric Models

\begin{tabular}{lccccc}
\hline & $\chi^{2}$ & $d f$ & RMSEA & AGFI & PGFI \\
\hline Model 1 & 2704.83 & 436 & 0.047 & 0.85 & 0.72 \\
Model 2 & 2422.41 & 406 & 0.045 & 0.86 & 0.72 \\
Model 3 & 2041.55 & 379 & 0.043 & 0.87 & 0.73 \\
\hline
\end{tabular}


Then, the item with the smallest factor loading in this pair (Item 19) was removed. Furthermore, the correlation between the factors collaboration and automaton and that between the factors help and marginal were not statistically significant. Thus, these two correlations between factors were fixed to zero. Table 2 shows the goodness-of-fit indices (Model 3). An improvement of fit can be observed, despite the loss in number of degrees of freedom. Thus, Items 19 and 28 were not used in additional analyses and will not be used in a revised version of the measure.

Once the best congeneric model was obtained, the tau-equivalent and the parallel models were tested for their global structure. The chi-square statistics of the three models are shown in Table 2. The differences in chi-square values were statistically significant $(p<.01)$. However, some factors could fit the tau-equivalent or the parallel models, thus these models were tested for every factor by imposing restrictions in the same way, but only in one factor at a time, making no restrictions on the parameters of the other factors. The chi-square statistics of the models for the eight factors are shown in Table 3. All the differences in chi-square values were statistically significant $(p<.01)$. That suggests that the less restrictive model is preferable, in this case, the congeneric global model.

From this model, the reliability of each item and factor were estimated using the methods described previously. These results and factorial loadings are displayed in Table 4. All the factorial loadings were statistically significant $(p<.01)$. Items 23 and 32 presented the lowest loading $(\lambda=.36)$, and Item 25 the highest one $(\lambda=.94)$. The reliabilities of the factors showed very good values, except for the marginal factor $\left(r_{x x}=.61\right)$, with three items, which showed only a modest reliability. (If we had used Cronbach's alpha, which includes the error term and underestimates reliability, these would have been the results: control $=.73$, help $=.81$, automaton $=.72$, magical $=.58 ;$ collaboration $=.64 ;$ interest $=.56$; memory $=.70 ;$ and credulous $=.41$.)

Table 5 shows the correlations among the factors. All of them were statistically significant $(p<.01)$. However, there were three correlations with very small nonzero values (lower than .10) that could not be fixed to zero.

\section{Retest}

The eight $t$ tests carried out between the composite score of each factor were not statistically significant, except the $t$ test for the control factor $(t=-2.919, p<.05)$. However, in this case, the effect size (eta squared) was .12, and an effect size should explain at least $13 \%$ of the variance to be considered significant (Borenstein, Cohen, Rothstein, Pollack, \& Kane, 1990). Thus, the test-retest difference for control, 
Table 3

$\chi^{2}$ Indices for the Congeneric (Model 3), Tau-Equivalent, and Parallel Models

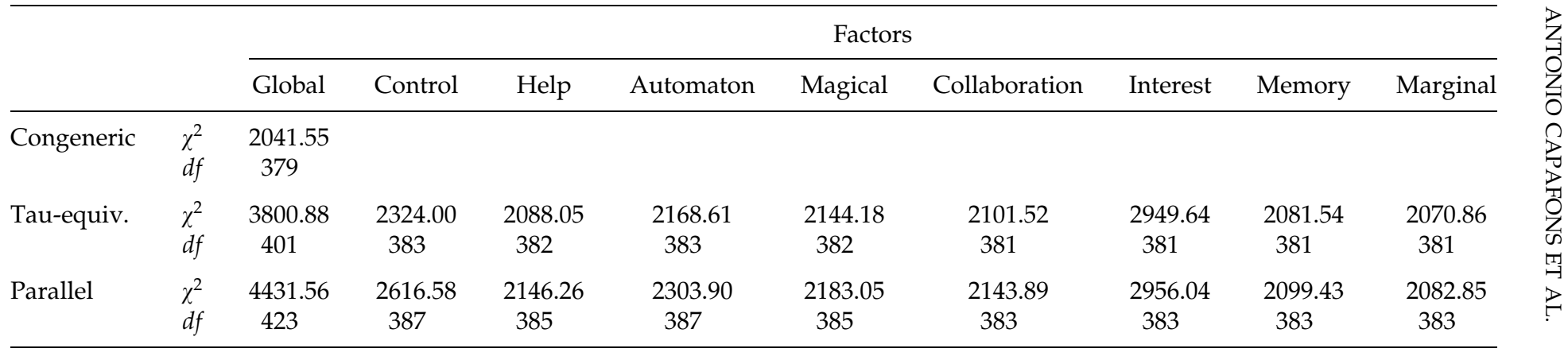


Table 4

Factor Loadings of the Final Model, Reliability of the Items $\left(\rho_{i i}\right)$, and Reliability of Each Factor $\left(r_{x x}\right)$

\begin{tabular}{|c|c|c|c|c|c|c|c|c|c|}
\hline & $r_{\mathrm{ii}}$ & Control & Help & Automaton & Magical & Collaboration & Interest & Memory & Marginal \\
\hline c1 & 0.42 & - & 0.65 & - & - & - & - & - & - \\
\hline c2 & 0.46 & - & - & - & - & 0.68 & - & - & - \\
\hline c3 & 0.22 & - & - & - & 0.47 & - & - & - & - \\
\hline c5 & 0.27 & - & - & - & 0.52 & - & - & - & - \\
\hline c6 & 0.69 & - & - & - & 0.83 & - & - & - & - \\
\hline c7 & 0.50 & - & - & 0.71 & - & - & - & - & - \\
\hline c8 & 0.29 & - & - & - & - & 0.54 & - & - & - \\
\hline c9 & 0.46 & - & - & - & 0.68 & - & - & - & - \\
\hline c10 & 0.68 & - & 0.83 & - & - & - & - & - & - \\
\hline c11 & 0.19 & - & - & 0.44 & - & - & - & - & - \\
\hline c12 & 0.65 & - & 0.81 & - & - & - & - & - & - \\
\hline c13 & 0.64 & - & - & - & - & 0.80 & - & - & - \\
\hline c14 & 0.48 & 0.69 & - & - & - & - & - & - & - \\
\hline c15 & 0.68 & 0.83 & - & - & - & - & - & - & - \\
\hline c17 & 0.38 & - & - & 0.61 & - & - & - & - & - \\
\hline c18 & 0.54 & - & - & 0.74 & - & - & - & - & - \\
\hline c20 & 0.33 & 0.57 & - & - & - & - & - & - & - \\
\hline c21 & 0.57 & - & - & 0.75 & - & - & - & - & - \\
\hline c22 & 0.55 & - & 0.74 & - & - & - & - & - & - \\
\hline c23 & 0.13 & 0.36 & - & - & - & - & - & - & - \\
\hline c24 & 0.68 & 0.83 & - & - & - & - & - & - & - \\
\hline c25 & 0.88 & - & - & - & - & - & 0.94 & - & - \\
\hline
\end{tabular}


Table 4

(continued)

\begin{tabular}{|c|c|c|c|c|c|c|c|c|c|}
\hline & $r_{\mathrm{ii}}$ & Control & Help & Automaton & Magical & Collaboration & Interest & Memory & Marginal \\
\hline c26 & 0.17 & - & - & - & - & - & -0.41 & - & - \\
\hline $\mathrm{c} 27$ & 0.41 & - & - & - & - & - & 0.64 & - & - \\
\hline c29 & 0.41 & - & - & - & - & - & - & 0.64 & - \\
\hline c30 & 0.50 & - & - & - & - & - & - & 0.71 & - \\
\hline c31 & 0.61 & - & - & - & - & - & - & 0.78 & - \\
\hline c32 & 0.13 & - & - & - & - & - & - & - & 0.36 \\
\hline c33 & 0.25 & - & - & - & - & - & - & - & 0.50 \\
\hline c34 & 0.36 & - & - & - & - & - & - & - & 0.60 \\
\hline$r_{x x}$ & & 0.87 & 0.93 & 0.87 & 0.82 & 0.84 & 0.81 & 0.87 & 0.61 \\
\hline
\end{tabular}


Table 5

Correlations Among Factors, Estimated by LISREL $(p<.01)$

\begin{tabular}{lrccccrr}
\hline & Control & Help & Automaton & Magical & Collaboration & Interest & Memory \\
\hline Help & 0.17 & & & & & & \\
Automaton & -0.57 & 0.06 & & & & & \\
Magical & 0.07 & 0.29 & 0.40 & - & & & \\
Collaboration & 0.16 & 0.52 & -0.19 & 0.11 & 0.28 & & \\
Interest & 0.23 & 0.48 & 0.47 & 0.48 & 0.26 & 0.21 & \\
Memory & -0.16 & 0.53 & 0.63 & 0.54 & -0.09 & -0.22 & 0.36 \\
Marginal & -0.16 & - & & & &
\end{tabular}


Table 6

Descriptive Statistics for Each Factor in Test and Retest

\begin{tabular}{|c|c|c|c|c|c|c|c|c|c|}
\hline & & Control & Help & Automaton & Magical & Collaboration & Interest & Memory & Marginal \\
\hline & Mean & 2.12 & 3.33 & 2.47 & 1.71 & 3.97 & 2.92 & 2.76 & 2.36 \\
\hline$(N=2404)$ & $S D$ & 0.86 & 0.93 & 0.96 & 0.68 & 0.82 & 1.05 & 1.08 & 0.87 \\
\hline Retest & Mean & 2.14 & 3.25 & 2.23 & 1.61 & 3.82 & 2.81 & 2.70 & 2.27 \\
\hline$(N=64)$ & $S D$ & 0.81 & 0.94 & 0.92 & 0.58 & 0.76 & 0.91 & 1.05 & 0.79 \\
\hline
\end{tabular}


although statistically significant, does not seem to affect the scale as a whole.

Table 6 includes the factor means and standard deviations for the test and retest.

\section{DISCUSSION}

Overall, we confirmed and extended the factor structure of the previous exploratory study (Capafons et al., 2003). Another main goal of the study was to determine the psychometric properties of the scale under the assumption-testing approach. The importance of testing which of the three models (congeneric, tau-equivalent, and parallel) fits the data better is that, if the assumptions of tau-equivalence are not met, there is an underestimation of the inner consistency of the susbscales when measured by the statistic alpha (Lord \& Novick, 1968; Novick \& Lewis, 1967). That is why, after determining the congeneric model that best represents the data, the tau-equivalent and parallel models were tested. As mentioned previously, the obtained goodness-of-fit indices for the final congeneric model (Model 3) indicated the best fit. The RMSEA indicated close fit of the model in relation to the degrees of freedom because its value was under the critical value .05 (Browne \& Cudeck, 1993), implying that the model explains a substantial amount of variance, as explained earlier. Also, the AGFI was close to .9, showing a close fit of the model (Jöreskog \& Sörbom, 1984, 1989). Finally, the PGFI did not suffer a decrement in the different tested models, despite the loss in degrees of freedom (Mulaik et al., 1989); there was no difference in quality for the models because, although every tested model had lower number of degrees of freedom, this index showed practically the same value. It indicated that the final congeneric model (Model 3) was the best one, not only for having the lowest RMSEA and AGFI but also for being the most parsimonious. With respect to the comparison among the congeneric with the tau-equivalent and the parallel models (Table 2), the obtained results indicated that the congeneric model (Model 3) showed better fit to the data than the other two models. This indicates that the best estimate of the reliability of the factors is not alpha but the one obtained by the method proposed by Werts et al. (1978). Only one subscale, marginal, showed only moderate reliability $\left(r_{x x}=.61\right)$. This result will be tested again and items may be added to increase its reliability.

Regarding the $t$ tests to evaluate the stability of the factors, only control had a significant difference between test and retest, although the effect size was so small that it cannot be considered an important difference. Overall, the results show a good stability of the factors, bearing in mind that the total scores are based on the observed scores, 
not on the true scores. If we had run a confirmatory factor analysis to assess longitudinal stability, we might have gotten unbiased estimates of the true stability of the measure, and the only significant difference probably would not have remained significant.

Overall, our results show that the scale has good psychometric properties, but in the final model, Items 23 and 32 showed very low factor loadings $(\lambda=.36)$ as compared with other items. These results should be evaluated in other samples, including those not involving students, because we cannot assume that clients/patients will necessarily have the same attributions, motivations, and so on, as students. Also, the factors marginal, collaboration, interest, and memory only have three items, and the first one has low reliability, so it would be worthwhile to add more items to them. The phrasing of Items 26, 32, and 34 will be simplified to avoid confusion. The answer format will be improved as it gives only one option for disagreement, compared with many options for agreement. A Likert-type scale is more appropriate. Finally, covariance structure models, which permit unbiased estimates of the temporal stability of scores, could be used. From a nonpsychometric perspective, future studies should evaluate if the scale can detect changes in attitudes and beliefs towards hypnosis after an intervention to change them and the role of attitudes and mistaken beliefs on the efficacy of hypnosis as a therapeutic adjunct.

\section{REFERENCES}

Barber, T. X. (1999). A comprehensive three-dimensional theory of hypnosis. In I. Kirsch, A. Capafons, E. Cardeña, \& S. Amigo (Eds.), Clinical hypnosis and self-regulation: Cognitive-behavioral perspectives (pp. 21-48). Washington, D.C.: American Psychological Association.

Blok, H., \& Saris, W. E. (1983). Using longitudinal data to estimate reliability. Applied Psychological Measurement, 7, 295-301.

Borenstein, M., Cohen, J., Rothstein, H. R., Pollack, S., \& Kane, J. M. (1990). Statistical power analysis for one-way analysis of variance: A computer program. Behavior Research Methods, Instruments and Computer, 22, 271-282.

Browne, M. W., \& Cudeck, R. (1993). Alternative ways of assessing model fit. In K. A. Bollen \& J. S. Long (Eds.), Testing structural equation models (pp. 136-162). Newbury Park, CA: Sage Publications.

Bryant, R. A. (1993). Beliefs about hypnosis: A survey of acute and chronic pain therapists. Contemporary Hypnosis, 10, 89-98.

Capafons, A. (1998). Hipnosis clínica: una visión cognitivo-comportamental [Clinical hypnosis: A cognitive-behavioral perspective]. Papeles del Psicólogo, 69, 71-88.

Capafons, A. (2001). Hipnosis [Hypnosis]. Madrid, Spain: Síntesis.

Capafons, A., Alarcón, A., Cabañas, S., \& Espejo, B. (2003). Análisis factorial exploratorio y propiedades psicométricas del cuestionario de creencias y actitudes hacia la hipnosis-cliente [Exploratory factorial analysis and psychometric properties of the Beliefs and Attitudes to Hypnosis Client Scale]. Psichotema, 15, 143-147.

Capafons, A., Cabañas, S., Alarcón, A., Espejo, B., Bustillo, A., \& Monje, A. (2004). Effects of different types of information on attitudes toward hypnosis. Manuscript submitted for publication. 
Cardeña, E. (1990, March). The concept(s) of trance. Paper presented at the annual meeting of the Society for the Anthropology of Consciousness, Pacific Palisades, CA.

Cardeña, E. (in press). The phenomenology of deep hypnosis: Quiescent and physically active. International Journal of Clinical and Experimental Hypnosis.

Cardeña, E., \& Spiegel, D. (1991). Suggestibility, absorption, and dissociation: An integrative model of hypnosis. In J. F. Schumaker (Ed.), Human suggestibility: Advances in theory, research and application (pp. 93-107). New York: Routledge.

Chaves, J. F. (1999). Applying hypnosis in pain management: Implications of alternative theoretical perspectives. In I. Kirsch, A. Capafons, E. Cardeña, \& S. Amigó (Eds.), Clinical hypnosis and self-regulation (pp. 227-247). Washington, DC: American Psychological Association.

Eimer, B. N., \& Freeman, A. (1998). Pain management psychotherapy: A practical guide. New York: John Wiley \& Sons.

Gow, K., Mackie, C., Clohessy, D., Cowling, T., \& Maloney, R. (2002, November). Opinions about hypnosis in Australia. Paper presented at the annual meeting of the Society for Clinical and Experimental Hypnosis, Boston, MA.

Green, J. P. (2003). Beliefs about hypnosis: Popular beliefs, misconceptions, and the importance of experience. International Journal of Clinical and Experimental Hypnosis, 51, 369-381.

Jöreskog, K. G. (1971). Statistical analysis of sets of congeneric tests. Psychometrika, 109-133.

Jöreskog, K. G., \& Sörbom, D. (1984). LISREL VI. Mooresville, IN: Scientific Software.

Jöreskog, K. G., \& Sörbom, D. (1989). LISREL 7. A guide to the program and applications (2nd ed.). Chicago: Scientific Software.

Jöreskog, K. G., \& Sörbom, D. (1999). LISREL 8.30 and PRELIS 2.30. Chicago: Scientific Software International.

Jöreskog, K. G., Sörbom, D., du Toit, S., \& du Toit, M. (1999). LISREL 8: New statistical features. Chicago: Scientific Software International.

Keller, R. F. (1996). Hypnosis belief survey. Psychological Hypnosis, 5, 8-9.

London, P. (1961). Subject characteristics in hypnosis research: I. Survey of experience, interest and opinion. International Journal of Clinical and Experimental Hypnosis, 9, 151-161.

Lord, F. M., \& Novick, M. R. (1968). Statistical theories of mental test scores. Reading, MA: Addison-Wesley.

McConkey, K. M. (1986). Opinions about hypnosis and self-hypnosis before and after hypnotic testing. International Journal of Clinical and Experimental Hypnosis, 34, 311-319.

McConkey, K. M., \& Jupp, J. J. (1985/1986). A survey of opinions about hypnosis. British Journal of Experimental and Clinical Hypnosis, 3, 87-93.

McIntosh, I. B., \& Hawney, M. (1983). Patients' attitudes to hypnotherapy in a general medical practice: A brief communication. International Journal of Clinical and Experimental Hypnosis, 31, 219-223.

Meyer, E., \& Lynn, S. J. (2002, November). Beliefs regarding the hypnotic trance, suggestibility, and experiences. Paper presented at the annual meeting of the Society for Clinical and Experimental Hypnosis, Boston, MA.

Mulaik, S. A., James, L. R., Van Alstine, J., Bennett, N., Lind, S., \& Stilwell, C. D. (1989). Evaluation of goodness-of-fit indices for structural equation models. Psychological Bulletin, 105, 430-445.

Nickisson, J. W. (1997). Hypnosis: Attitudes, knowledge, and prior experience among psychology and nursing students. Unpublished master's thesis, University of Northern Colorado, Greeley, CO.

Novick, M. R., \& Lewis, C. (1967). Coefficient alpha and the reliability of composite measurements. Psychometrika, 32, 1-13.

Schoenberger, N. E., Kirsch, I., Gearan, P., Montgomery, G., \& Pastyrnak, S. L. (1997). Hypnotic enhancement of a cognitive-behavioral treatment for public speaking anxiety. Behavior Therapy, 28, 127-140. 
Spanos, N. P., Brett, P. J., Menary, E. P., \& Cross, W. P. (1987). A measure of attitudes toward hypnosis: Relationship with absorption and hypnotic susceptibility. American Journal of Clinical Hypnosis, 30, 139-150.

Steiger, J. H. (1990). Structural model evaluation and modification: An interval estimation approach. Multivariate Behavioral Research, 25, 173-180.

Steiger, J. H., \& Lind, J. M. (1980, May). Statistically based tests for the number of common factors. Paper presented at the annual meeting of the Psychometric Society, Iowa City, IA.

Ullman, J. B. (1996). Structural equation modeling. In B. G. Tabachnick \& L. S. Fidell (Eds.), Using multivariate statistics (3rd ed., pp. 709-812). New York: Harper Collins.

Werts, C. E., Breland, H. M., Grandy, J., \& Rock, D. R. (1980). Using longitudinal data to estimate reliability in the presence of correlated measurement errors. Educational and Psychological Measurement, 30, 19-29.

Werts, C. E., Rock, D. R., Linn, R. L., \& Jöreskog, K. G. (1978). A general method of estimating the reliability of a composite. Educational and Psychological Measurement, 38, 933-938.

\section{APPENDIX}

The Beliefs and Attitudes to Hypnosis Valencia Scale-Client ${ }^{3}$

You will find below some questions that will help us determine your opinion about hypnosis. Please let us know your level of agreement with the statements printed below, writing the number that best represents your opinion, according to the following scale:

1 - I disagree

2 - I agree slightly

3 - I agree moderately

4 - I agree quite a bit

5 - I agree completely

1. Hypnosis may be very helpful to others.

2. Hypnosis requires cooperation between therapist and client.

3. I need to be in a deep trance to obtain my goals.

4. Hypnosis scares me.

5. Under hypnosis I can achieve things without making any effort.

6. Hypnosis can be a magical solution to my problems.

7. I believe that under hypnosis I am a robot under the control of the hypnotist.

8. Hypnosis requires effort on the part of the hypnotized person.

9. Hypnosis is all I would need to solve my problems.

10. Hypnosis can be of great assistance in a psychological treatment.

${ }^{3}$ For a copy of the complete questionnaire contact Antonio Capafon. Translation of the original scale used in this study. 
11. The hypnotized person is passive.

12. Hypnosis is a complement or tool to help psychological therapies.

13. To hypnotize someone it is necessary to have his or her collaboration.

14. When I hypnotize myself I can come out of hypnosis whenever I want.

15. Under hypnosis, I keep the will to do what I want.

16. Hypnosis encourages self-control.

17. I am afraid to stay "stuck" in a deep trance.

18. I believe that under hypnosis you can lose control of yourself.

19. I believe that hypnosis can be dangerous.

20. I produce everything that occurs to me under hypnosis.

21. Under hypnosis, I can be compelled to do things I do not want.

22. Hypnosis makes therapeutic results easier.

23. Under hypnosis, I can ignore any suggestion that I do not agree with or do not want to carry out.

24. When I am hypnotized, I maintain self-control.

25. I would like to be hypnotized.

26. I would not let myself be hypnotized if someone tried to do it.

27. I would like to be very hypnotizable.

28. You can learn faster under hypnosis.

29. What is recalled under hypnosis is always true.

30. It is impossible to lie under hypnosis, although the hypnotized person may want to.

31. A way to confirm that an event occurred is that the person recalls it under hypnosis.

32. Hypnosis is a trance state involving a dissociation.

33. Hypnosis is outside scientific research.

34. In general, the characteristics of very hypnotizable people are: credulity, ignorance, dependency, and psychological disturbances.

\author{
Konfirmatorische Faktorenanalyse der Valencia-Skala \\ zur Messung von Einstellungen und Erwartungen \\ bezüglich Hypnose: Eine internationale Studie
}

\title{
Antonio Capafons, Sonia Cabañas, Begoña Espejo, und Etzel Cardeña
}

Zusammenfassung: Anschauungen bezüglich Hypnose üben einen wichtigen Einfluss auf Bereiche wie anfänglicher Rapport und Behandlungscompliance aus. Bei der Valencia-Skala zur Messung von Einstellungen und Erwartungen bezüglich Hypnose handelt es sich um das vermutlich erste Instrument, das speziell für eine Spanisch sprechende Population entwickelt wurde. Zusätzlich zur Messung der Einstellungen, kann die Skala dazu 
beitragen, die Auswirkungen klinischer und experimenteller Interventionen auf die Einstellungen und Erwartungen gegenüber Hypnose zu ermitteln. Der Artikel stellt das Ergebnis eine konfirmatorischen Faktorenanalyse von Daten aus 5 verschiedenen Ländern $(n=2.402)$ dar. Retest-Daten wurden dabei ebenfalls erhoben. Es ergab sich eine statistische Bestätigung der 8-faktoriellen Struktur: Automatismus, Hilfe, Personale Kontrolle, Interesse, magische Lösung, Mitarbeit, Gedächtnis und Sonstiges. Außerdem wurden gute Reliabilitäten für die einzelnen Faktoren gefunden. Dabei wurden neue statistische Techniken anstelle von Cronbachs Alpha verwendet, da Cronbachs Alpha die Reliabilität unterschätzen könnte.

\title{
RALF SCHMAELZLE
}

University of Konstanz, Konstanz, Germany

\begin{abstract}
Analyse factorielle venant confirmer l'échelle de Valence sur les Attitudes et les Croyances envers l'hypnose:

Etude internationale
\end{abstract}

\section{Antonio Capafons, Sonia Cabañas, Begoña Espejo, et Etzel Cardeña}

Résumé : les connaissances liées à l'hypnose ont un impact considérable dans des domaines tels que le premier contact et le fait de se conformer au traitement hypnotique. L'échelle de Valence sur les Attitudes et les Croyances envers l'hypnose est probablement le premier instrument spécifiquement orienté vers une population hispanophone. En plus de mesurer les connaissances liées à l'hypnose, cette échelle peut aussi aider à évaluer les effets de manipulations cliniques et expérimentales sur les attitudes et croyances de sujets envers l'hypnose. L'article présente une analyse de facteur venant confirmer cette échelle utilisée sur un échantillon à travers 5 pays différenst $(N=2402)$. Des analyses de test et re-test ont aussi été effectuées. Les auteurs ont trouvé une confirmation statistique pour un modèle de solution à 8 facteurs: automatisme, aide, contrôle personnel, intérêt, solution magique, collaboration, mémoire et marginal. Ils ont aussi obtenu de bonnes estimations de fiabilité pour chaque facteur en utilisant des techniques statistiques au lieu de l'alpha de Cronbach (coefficient alpha) qui peut sous-estimer la fiabilité.

VICTOR SIMON

Psychosomatic Medicine \& Clinical Hypnosis Institute, Lille, France

Análisis factorial confirmatorio de la Escala de Valencia de Actitudes y Creencias Hacia la Hipnosis:

Un estudio internacional

\section{Antonio Capafons, Sonia Cabañas, Begoña Espejo, y Etzel Cardeña}

Resumen: Las cogniciones sobre la hipnosis juegan un importante papel en áreas como el rapport inicial y la conformidad con el tratamiento hipnótico. 
Probablemente la Escala de Valencia de Actitudes y Creencias Hacia la Hipnosis es el primer instrumento diseñado específicamente para la población Hispanoparlante. Además de medir estas cogniciones, la escala puede ayudar a evaluar el efecto de manipulaciones clínicas y experimentales en las actitudes y creencias hacia la hipnosis. El artículo presenta un análisis factorial confirmatorio con una muestra de cinco países diferentes $(N=2,402)$. También analizamos la confiabilidad del instrumento. Encontramos confirmación estadística para una solución de 8 factores: automatismo, ayuda, control personal, interés, solución mágica, colaboración, memoria, y marginal. También obtuvimos buenas estimaciones de la confiabilidad de cada factor usando nuevas técnicas estadísticas, en vez del alfa de Cronbach que tiende a subestimar la confiabilidad.

ETZEL CARDEÑA

University of Texas-Pan American, Edinburg, Texas, USA 